\title{
The Future of Biologic Agents in the Treatment of Sjögren's Syndrome
}

\author{
Jiska M. Meijer • Justin Pijpe • Hendrika Bootsma • \\ Arjan Vissink • Cees G. M. Kallenberg
}

Published online: 11 September 2007

(C) Humana Press Inc. 2007

\begin{abstract}
The gain in knowledge regarding the cellular mechanisms of $\mathrm{T}$ and $\mathrm{B}$ lymphocyte activity in the pathogenesis of Sjögren's syndrome (SS) and the current availability of various biological agents (anti-TNF- $\alpha$, IFN$\alpha$, anti-CD20, and anti-CD22) have resulted in new strategies for therapeutic intervention. In SS, various phase I and II studies have been performed to evaluate these new strategies. Currently, B cell-directed therapies seem to be more promising than $\mathrm{T}$ cell-related therapies. However, large, randomized, placebo-controlled clinical trials are needed to confirm the promising results of these early studies. When performing these trials, special attention has to be paid to prevent the occasional occurrence of the severe side effects.
\end{abstract}

Keywords Sjögren's syndrome · Biological agent .

Treatment $\cdot$ Monoclonal antibody Therapy .

Autoimmune disease

\section{Introduction}

Sjögren's syndrome (SS) is a chronic lymphoproliferative autoimmune disease with disturbances of $\mathrm{T}$ lymphocytes, $\mathrm{B}$ lymphocytes, and exocrine glandular cells [1]. SS can be

J. M. Meijer $(\triangle) \cdot$ J. Pijpe $\cdot$ A. Vissink

Department of Oral and Maxillofacial Surgery,

University Medical Center Groningen, University of Groningen, P.O. Box 30.001, 9700 RB Groningen, The Netherlands

e-mail: j.m.meijer@kchir.umcg.nl

H. Bootsma $\cdot$ C. G. M. Kallenberg

Department of Rheumatology and Clinical Immunology, University Medical Center Groningen, University of Groningen, Groningen, The Netherlands primary (pSS) or secondary SS (sSS), the latter being associated with another autoimmune disease [e.g., rheumatoid arthritis, systemic lupus erythematosus (SLE)].

Lymphocytic infiltrates are a characteristic histopathological finding in SS. These infiltrates consist of T and B cells. The expression of different cytokines, such as tumor necrosis factor- $\alpha$ (TNF- $\alpha$ ) and interferon- $\alpha$ (IFN- $\alpha$ ), during the formation and proliferation of these infiltrates has been investigated. There is an overexpression of TNF$\alpha$, which is secreted by CD4+ T lymphocytes, mononuclear cells, and epithelial cells [2]. The intraglandular synthesis of TNF- $\alpha$ causes destruction of acini by up-regulation of Fas at the surface of the glandular epithelial cells, stimulation of secretion of type 2 and 9 matrix metalloproteases by epithelial cells, and overexpression of different chemokines [3-5]. IFN- $\alpha$ is produced by activated plasmacytoid dendritic cells in primary SS (pSS), and numerous IFN- $\alpha$-producing cells have been detected in labial salivary glands [6]. IFN- $\alpha$ promotes the autoimmune process by increasing autoantibody production and through the formation of endogenous IFN-á inducers. IFNs have potent immunomodulating properties and are thought to trigger a systemic biological response [7].

Besides the presence of proinflammatory cytokines, described in the previous paragraph, recent studies have shown an important role for B cells in the pathogenesis of SS. Presence of autoantibodies and hypergammaglobulinemia are both considered to reflect B cell hyperactivity. Systemic complications of SS are associated with this B cell hyperactivity [8]. Moreover, about $5 \%$ of SS patients develop malignant B cell lymphoma [9]. B cell activating factor (BAFF), also known as B lymphocyte stimulator (BLyS), is an important factor in local and systemic autoimmunity [1]. Dysregulated BAFF expression is implicated in disease progression and perpetuation of humoral 
autoimmunity. Overproduction of BAFF in transgenic mice has been shown to result in $\mathrm{B}$ cell proliferation and antibody production resulting in inflammation and destruction of the salivary glands, as well as kidney failure similar to observations seen in SLE [10]. In humans, circulating BAFF levels are increased in patients with pSS and correlate with disease activity [11].

Recent insights in the cellular mechanisms of $\mathrm{T}$ and $\mathrm{B}$ lymphocyte activity in the pathogenesis of SS and the current availability of various biological agents have resulted in new strategies for therapeutic intervention. The use of these biological agents in the treatment of SS will be discussed in this review.

\section{Biological Agents}

Currently, biological agents have been introduced in various systemic autoimmune diseases, as rheumatoid arthritis and SLE. Biological agents most frequently applied in autoimmune diseases are monoclonal antibodies, soluble receptors, and molecular imitators [12]. These biological agents enhance or replace conventional immunosuppressive therapy. In contrast to rheumatoid arthritis and SLE, no biological agent has been approved yet for the treatment of SS, but several phase II and III studies have been or are currently conducted. The biological agents used in SS trials are IFN- $\alpha$ and agents targeting TNF- $\alpha$ and B cells (anti$\mathrm{CD} 20$, anti-CD22). Although no trials have been performed yet with BAFF antagonists, this might be a promising therapy [13] and will be discussed in this review, as well.

\section{Anti-TNF- $\alpha$ Monoclonal Antibodies}

There are three main biological agents targeting TNF- $\alpha$ : the chimeric monoclonal IgG1 antibody infliximab, the receptor fusion protein etanercept, and the fully humanized monoclonal antibody adalimumab.

In an open-label study, short-term treatment with infliximab was reported to be very effective in active pSS over a 3-month period [14]. Sixteen patients received three infusions $(3 \mathrm{mg} / \mathrm{kg})$ at weeks 0,2 , and 6 , which led to significant improvement in all clinical and functional parameters, including global assessments, erythrocyte sedimentation rate, whole salivary flow rate, tear secretion (Schirmer test), tender joint count, fatigue score, and sensation of dry eyes and dry mouth. Three patients, all with short disease duration ( $<3$ years), were considered to be in complete remission up till 1 year. In 10 out of the 16 patients, SS symptoms, particularly mouth dryness, relapsed after a median of 9 weeks. In a follow-up study, a maintenance regimen of one infusion every 12 weeks was evaluated in these 10 patients. Retreatment induced an improvement of signs related to SS that was comparable with the effects from the three loading infusions [15]. To confirm these promising results from an uncontrolled study, the Trial of Remicade In Primary Sjögren's Syndrome study was designed. In this multicenter, double-blinded, placebocontrolled, randomized clinical trial, 103 patients with active pSS were included and treated with infliximab infusions $(5 \mathrm{mg} / \mathrm{kg}$ ) or placebo at weeks 0,2 , and 6 . Follow-up was 22 weeks. Primary endpoint was an improvement of $>30 \%$ of two of three VAS scores measuring joint pain, fatigue, and dry eyes. There were several secondary endpoints of which one was the basal salivary flow rate. In contrast to the previously mentioned uncontrolled studies, no evidence of efficacy of infliximab treatment on all clinical and functional parameters could be demonstrated in this randomized controlled clinical trial [2].

A trial on $15 \mathrm{pSS}$ patients (mean disease duration 3.6 years) with $25-\mathrm{mg}$ etanercept, subcutaneously twice a week for 12 weeks, did not reveal a reduction in sicca symptoms and signs, neither did the repeated treatment for up to 26 weeks. Only in the subset of four patients with severe fatigue a decrease in fatigue was observed [16]. Another trial evaluating subcutaneous administration of etanercept vs placebo for 12 weeks (28 patients) also showed no clinical efficacy [17]. No trials of adalimumab treatment in pSS have been reported in the literature yet.

In conclusion, TNF-targeting treatment could not be proven to be of benefit in reducing the complaints of pSS patients.

\section{IFN- $\alpha$}

IFNs are proteins with antiviral activity and potent immunomodulating properties. SS patients have an activated type I IFN system [6]. Such a role for IFN- $\alpha$ appears to contradict the reports described below, that low doses of IFN- $\alpha$ administered via the oromucosal route increase the unstimulated salivary output. However, it is hypothesized that oral IFN- $\alpha$ treatment may act by increasing saliva secretion by up-regulation of aquaporin 5 transcription without significantly influencing the underlying autoimmune process [6, 7].

In a phase II study, treatment of pSS patients with IFN- $\alpha$ administered via the oromucosal route (by dissolving lozenges) was demonstrated to be effective (improvement of salivary output, decreased complaints of xerostomia) and safe [18]. Based on these promising results, a randomized, parallel group, double-blinded, placebo-controlled clinical trial (497 pSS patients) was designed. Patients were randomized into two groups and received a 24 -week daily treatment with either 450 IU IFN- $\alpha$ (150 IU three times per day) or placebo in a ratio $3: 2$, administered by the oromucosal route. This randomized, controlled clinical trial failed to demonstrate a significant effect on the primary endpoints (VAS score for oral dryness and stimulated whole 
salivary flow) in the IFN- $\alpha$ group relative to the placebo group. There was a significant increase in unstimulated whole saliva in the patients treated with IFN- $\alpha$, which correlated positively and significantly with improvement in seven of eight symptoms associated with oral and ocular dryness. No adverse events were observed [7].

In conclusion, no clinical evidence for the efficacy of IFN$\alpha$ treatment in pSS patients has been shown yet; however, an improvement of unstimulated whole saliva was observed. Further research is needed to objectify the effect of IFN-á on salivary gland tissue.

\section{Anti-CD20 Monoclonal Antibodies}

Anti-CD20 (rituximab) is a chimeric humanized monoclonal antibody specific for the B cell surface molecule CD20, which is expressed on the surface of normal and malignant pre-B and mature B lymphocytes. CD20 mediates B cell proliferation and differentiation. This antibody has been demonstrated to prevent $\mathrm{B}$ cells from proliferating and to induce lysis of B cells by complement-dependent and antibody-dependent cytotoxicity mechanisms as well as by direct induction of apoptosis [19].

Rituximab is currently used for the treatment of low-grade B cell lymphomas [20]. In controlled studies, it was shown to be safe and effective in the treatment of rheumatoid arthritis [21-23]. Moreover, open-label studies in SLE patients are promising [24].

In an open-label phase II study, 15 patients with pSS were treated with 4 infusions of rituximab $\left(375 \mathrm{mg} / \mathrm{m}^{2}\right.$ once weekly) and followed up for a 3-month period. Eight of the 15 patients were early pSS patients (mean disease duration 28 months, all had residual salivary gland function at baseline), and 7 patients had a concomitant mucosaassociated lymphoid tissue (MALT) lymphoma (mean disease duration 79 months).

In the early pSS patients, rituximab treatment resulted in significant improvement of subjective symptoms and an increase in salivary gland function. All patients showed a rapid depletion of peripheral $\mathrm{B}$ cells within a few weeks, accompanied by a decrease in IgM-RF levels [8]. Repeated parotid gland biopsies in five of the early patients after treatment showed redifferentation of the lymphoepithelial duct lesions into normal striated ducts, possibly indicating regeneration of salivary gland tissue (unpublished data).

Five of the eight pSS patients without a MALT lymphoma received a second course of rituximab (after 9-11 months) due to recurrence of symptoms. Retreatment resulted in the same significant improvement of the salivary flow rate and subjective symptoms compared to the results of the first treatment, together with a decrease in B cells and IgM-RF levels.

Six of the seven MALT/pSS patients were initially effectively treated with rituximab. The remaining MALT/
pSS patient had progressive MALT disease and severe extraglandular SS disease within 3 months after the start of rituximab treatment. Cyclophosphamide was added, which led to stable disease of both MALT and SS. One of the six patients initially responding had a recurrence of MALT lymphoma after 9 months and was successfully retreated with rituximab. The other patients are still in remission (unpublished data).

In another open-label study, $16 \mathrm{pSS}$ patients received only two weekly rituximab infusions $\left(375 \mathrm{mg} / \mathrm{m}^{2}\right)$, with a follow-up of 36 weeks. Again, treatment resulted in rapid complete depletion of peripheral B cells. At week 12, a significant improvement of VAS scores for fatigue and dryness was recorded, and at week 36 , a significant improvement for VAS scores for global disease, fatigue, dry mouth, dry eyes, and dry vagina, but also in the number of tender joint and tender joint counts was seen [25]. Both in the study of Pijpe et al. [8] and the study of DevauchellePensec et al. [25], patients with a short disease duration showed more improvements than patients with longer disease duration.

Two trials retrospectively evaluated the effect of rituximab (four infusions of $375 \mathrm{mg} / \mathrm{m}^{2}$ ) in $18 \mathrm{pSS}$ patients (mean disease duration 10 years) with systemic features. Self-reported dryness improved in six patients (VAS scores not known for three patients, no improvement in the other nine patients). Both studies reported good efficacy of the treatment on systemic features [26, 27].

In conclusion, in phase II trials, it has been shown that rituximab seems to be effective for at least 6-9 months in pSS patients with active disease, improving both subjective and objective complaints. Retreatment with rituximab resulted in a similar good clinical response. In pSS patients with longer disease duration, without residual salivary gland function, rituximab treatment seems to be effective for systemic features. To confirm these promising results, randomized placebo-controlled clinical trials are needed.

\section{Anti-CD22 Monoclonal Antibodies}

Epratuzumab is a fully humanized monoclonal antibody specific for the B cell surface molecule CD22. CD22 is expressed on the surface of normal mature and malignant $\mathrm{B}$ lymphocytes. CD22 appears to be involved in the regulation of $\mathrm{B}$ cell activation through $\mathrm{B}$ cell receptor signaling and cell adhesion [28]. In an open-label phase I/II study, safety and efficacy of epratuzumab were investigated in 16 pSS patients. Follow-up was 6 months. These pSS patients received four doses of $360 \mathrm{mg} / \mathrm{m}^{2}$ epratuzumab intravenously. Mean disease duration before therapy was 2.9 years, and none of the patients had received prior B cell-targeted therapy. Most improvements occurred in the Schirmer test, unstimulated whole salivary flow and the VAS score for 


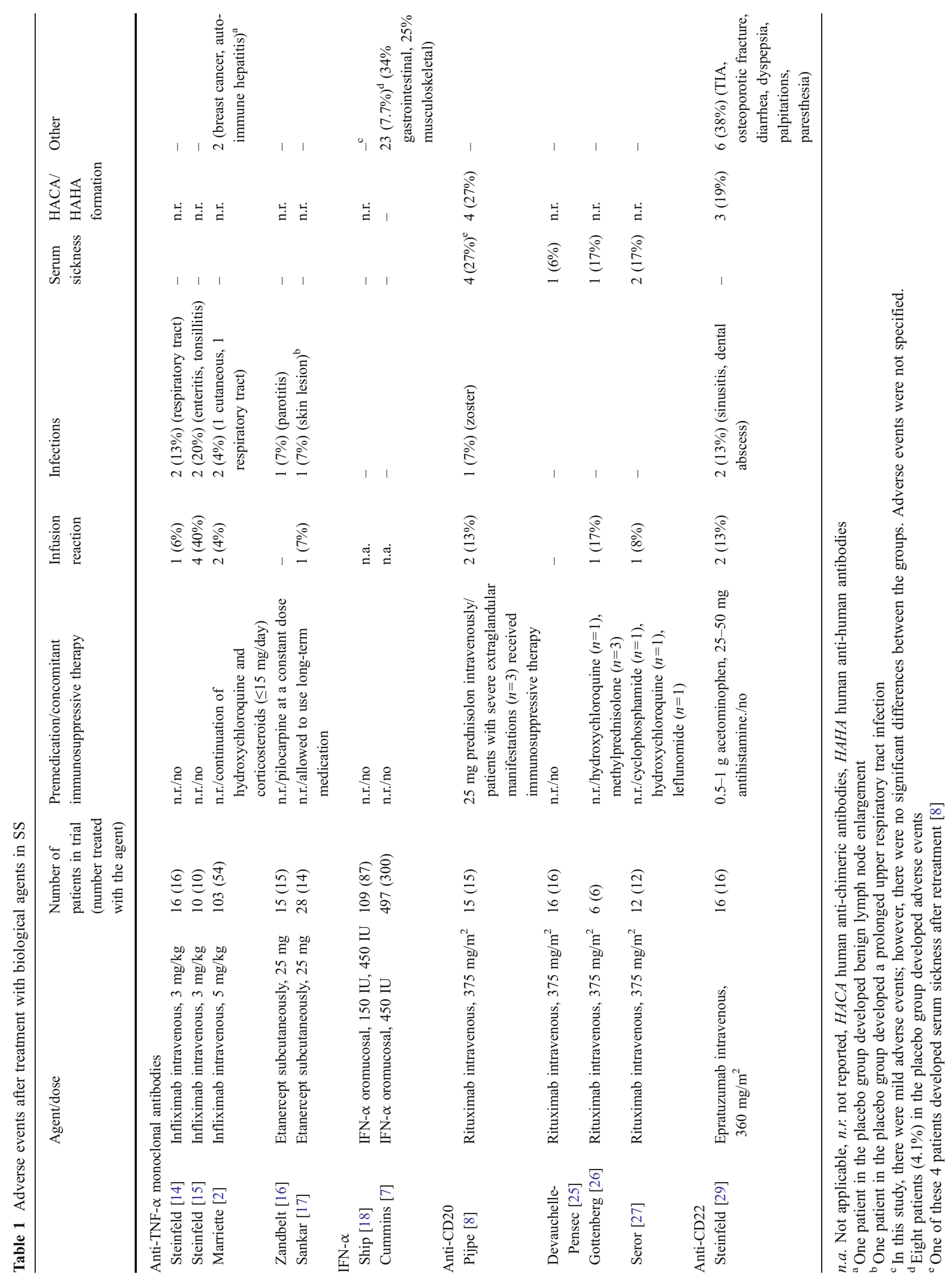


fatigue. The new developed disease activity score consisted of the four domains: dryness of the eyes, dryness of the mouth, fatigue, and laboratory parameters. Based on this score, $53 \%$ achieved at least $20 \%$ improvement in at least two domains at 6 weeks. Corresponding rates for 10, 18, and 32 weeks are 53, 47, and $67 \%$. Remarkably, the number of responders was higher 6 months after the treatment administration than earlier. Peripheral B cells decreased with a median decrease of 54 and $39 \%$ at 6 and 18 weeks, respectively.

In conclusion, epratuzumab seems to be an effective treatment. Randomized, placebo-controlled clinical trials are needed before epratuzumab can be advised for general treatment in pSS patients [29].

\section{Anti-BAFF}

BAFF is a B cell-activating factor that acts as a positive regulator of $\mathrm{B}$ cell function and expansion. BAFF levels were found elevated in serum and saliva in SS patients, but no correlation could be shown between serum and saliva levels [30]. However, circulating levels of BAFF in pSS patients were shown to be a marker for disease activity [11].

To the best of our knowledge, no trials have been performed with anti-BAFF treatment in SS yet, but such an approach might be considered for future trials. Currently, two human BAFF antagonists have been developed, a human antibody (anti-BLyS) that binds to soluble BAFF and a fusion protein of one of the BAFF receptors [31, 32]. Especially, SS patients with elevated BAFF levels, hypergammaglobulinemia, elevated levels of autoantibodies, and associated B cell lymphoma might be candidates for antiBAFF treatment [33].

\section{Safety and Tolerability of Biological Agents}

The most important side effects of treatment with biological agents are direct mild infusion reactions. Several patients developed a serum sickness-like disease a few days after the second infusion that might be related to the formation of antibodies against the biological agent [human anti-chimeric antibodies (HACAs) or human anti-human antibodies]. A few patients developed infections during treatment with a biological agent; however, some patients concomitantly used other immunosuppressive therapies. Therefore, the direct relation between the biological agent and the infection is unsure. All adverse events reported in the trials described in this review are reported in Table 1. According to this table, the most frequent side effects of treatment with biological agents are mild infusion reactions. The most severe side effect of the various treatments used in SS patients was the development of a serum sickness-like disease. This adverse effect of treatment occurred in $16 \%(8$ of 49) of the patients treated with rituximab. HACA formation was observed in patients developing a serum sickness-like disease and occurred only in patients receiving low-dose corticosteroids and no other immunosuppressive drugs. It is assumed that higher doses of corticosteroids during treatment might prevent the occurrence of serum sickness.

\section{Future Perspectives}

Biological agents are promising therapies for SS. Randomized studies failed to show a clinical effect of anti-TNF- $\alpha$ and IFN- $\alpha$ in the treatment of SS. Notwithstanding the unfortunate results of anti-TNF- $\alpha$ and IFN- $\alpha$, B cell depletion (both anti-CD20 and anti-CD22) seems very promising. Again, this promising effect, as was previously also assumed for anti-TNF- $\alpha$ and IFN- $\alpha$, must be confirmed in larger randomized controlled clinical trials.

HACAs have been reported to occur at a higher rate in patients with an autoimmune disease. It seems that monoclonal antibodies are more immunogenic in active autoimmune disease, independent of the type of disease. Additional use of immunosuppressive therapy in these patients might be mandatory to prevent serious side effects. These unwanted side effects might also be prevented by the use of fully humanized antibodies. The currently available humanized antibodies are promising, but need further study. Moreover, there is still a need for improved assessment parameters to monitor treatment effects, both subjectively and objectively. For studies on intervention of SS, evaluation of the parotid gland might be of use because function, composition of saliva, and histology can be evaluated on the same gland at different time points. Activity scores are currently under development by Bowman and Vitali $[34,35]$. Finally, as soon as effective intervention treatments have been established, the cost-effectiveness of these currently very expensive antibodies needs to be analyzed to select those patients that might benefit the most from this kind of treatment.

\section{References}

1. Hansen A, Lipsky PE, Dorner T (2005) Immunopathogenesis of primary Sjogren's syndrome: implications for disease management and therapy. Curr Opin Rheumatol 17:558-565

2. Mariette X, Ravaud P, Steinfeld S, Baron G, Goetz J, Hachulla E et al (2004) Inefficacy of infliximab in primary Sjogren's syndrome: results of the randomized, controlled Trial of Remicade in Primary Sjogren's Syndrome (TRIPSS). Arthritis Rheum 50:1270-1276 
3. Azuma M, Aota K, Tamatani T, Motegi K, Yamashita T, Harada K et al (2000) Suppression of tumor necrosis factor alpha-induced matrix metalloproteinase 9 production by the introduction of a superrepressor form of inhibitor of nuclear factor kappaBalpha complementary DNA into immortalized human salivary gland acinar cells. Prevention of the destruction of the acinar structure in Sjogren's syndrome salivary glands. Arthritis Rheum 43:1756-1767

4. Cuello C, Palladinetti P, Tedla N, Di Girolamo N, Lloyd AR, McCluskey PJ et al (1998) Chemokine expression and leucocyte infiltration in Sjogren's syndrome. Br J Rheumatol 37:779-783

5. Matsumura R, Umemiya K, Goto $T$, Nakazawa $T$, Ochiai $K$, Kagami $M$ et al (2000) Interferon gamma and tumor necrosis factor alpha induce Fas expression and anti-Fas mediated apoptosis in a salivary ductal cell line. Clin Exp Rheumatol $18: 311-318$

6. Bave U, Nordmark G, Lovgren T, Ronnelid J, Cajander S, Eloranta ML et al (2005) Activation of the type I interferon system in primary Sjogren's syndrome: a possible etiopathogenic mechanism. Arthritis Rheum 52:1185-1195

7. Cummins MJ, Papas A, Kammer GM, Fox PC (2003) Treatment of primary Sjogren's syndrome with low-dose human interferon alfa administered by the oromucosal route: combined phase III results. Arthritis Rheum 49:585-593

8. Pijpe J, van Imhoff GW, Spijkervet FKL, Roodenburg JL, Wolbink GJ, Mansour K et al (2005) Rituximab treatment in patients with primary Sjogren's syndrome: An open-label phase II study. Arthritis Rheum 52:2740-2750

9. Voulgarelis M, Dafni UG, Isenberg DA, Moutsopoulos HM (1999) Malignant lymphoma in primary Sjogren's syndrome: a multicenter, retrospective, clinical study by the European Concerted Action on Sjogren's Syndrome. Arthritis Rheum 42:17651772

10. Pers JO, Daridon C, Devauchelle V, Jousse S, Saraux A, Jamin C et al (2005) BAFF overexpression is associated with autoantibody production in autoimmune diseases. Ann N Y Acad Sci 1050:34-39

11. Szodoray P, Jellestad S, Alex P, Zhou T, Wilson PC, Centola M et al (2004) Programmed cell death of peripheral blood B cells determined by laser scanning cytometry in Sjogren's syndrome with a special emphasis on BAFF. J Clin Immunol 24:600-611

12. Kourbeti IS, Boumpas DT (2005) Biological therapies of autoimmune diseases. Curr Drug Targets Inflamm Allergy 4:41-46

13. d'Arbonneau F, Pers JO, Devauchelle V, Pennec Y, Saraux A, Youinou P (2006) BAFF-induced changes in B cell antigen receptor-containing lipid rafts in Sjogren's syndrome. Arthritis Rheum 54:115-126

14. Steinfeld SD, Demols P, Salmon I, Kiss R, Appelboom T (2001) Infliximab in patients with primary Sjogren's syndrome: a pilot study. Arthritis Rheum 44:2371-2375

15. Steinfeld SD, Demols P, Appelboom T (2002) Infliximab in primary Sjogren's syndrome: one-year follow-up. Arthritis Rheum 46:3301-3303

16. Zandbelt MM, De Wilde P, van Damme P, Hoyng CB, Van de Putte L, Van den Hoogen F (2004) Etanercept in the treatment of patients with primary Sjogren's syndrome: a pilot study. J Rheumatol 31:96-101

17. Sankar V, Brennan MT, Kok MR, Leakan RA, Smith JA, Manny J et al (2004) Etanercept in Sjogren's syndrome: a twelve-week randomized, double-blind, placebo-controlled pilot clinical trial. Arthritis Rheum 50:2240-2245

18. Ship JA, Fox PC, Michalek JE, Cummins MJ, Richards AB (1999) Treatment of primary Sjogren's syndrome with low-dose natural human interferon-alpha administered by the oral mucosal route: a phase II clinical trial. IFN Protocol Study Group. J Interferon Cytokine Res 19:943-951

19. Salama AD, Pusey CD (2006) Drug Insight: rituximab in renal disease and transplantation. Nature 2:221-230
20. McLaughlin P, Grillo-Lopez AJ, Link BK, Levy R, Czuczman MS, Williams ME et al (1998) Rituximab chimeric anti-CD20 monoclonal antibody therapy for relapsed indolent lymphoma: half of patients respond to a four-dose treatment program. J Clin Oncol 16:2825-2833

21. Edwards JC, Szczepanski L, Szechinski J, Filipowicz-Sosnowska A, Emery P, Close DR et al (2004) Efficacy of B-cell-targeted therapy with rituximab in patients with rheumatoid arthritis. $\mathrm{N}$ Engl J Med 350:2572-2581

22. Edwards JC, Cambridge G (2006) B-cell targeting in rheumatoid arthritis and other autoimmune diseases. Nat Rev Immunol 6:394403

23. Emery P, Fleischmann R, Filipowicz-Sosnowska A, Schechtman J, Szczepanski L, Kavanaugh A et al (2006) The efficacy and safety of rituximab in patients with active rheumatoid arthritis despite methotrexate treatment: results of a phase IIB randomized, double-blind, placebo-controlled, dose-ranging trial. Arthritis Rheum 54:1390-1400

24. Looney RJ, Anolik JH, Campbell D, Felgar RE, Young F, Arend LJ et al (2004) B cell depletion as a novel treatment for systemic lupus erythematosus: a phase I/II dose-excalation trial of rituximab. Arthritis Rheum 50:2580-2589

25. Devauchelle-Pensec V, Pennec Y, Morvan J, Pers JO, Daridon C, Jousse-Joulin S, Roudaut A, Jamin C, Renaudineau Y, Quintin Roué I, Cochener B, Youinou P, Saraux A (2007) Improvement of Sjogren's syndrome after two infusions of rituximab (anti-CD20). Arthritis Care Res 57(2):310-317

26. Gottenberg JE, Guillevin L, Lambotte O, Combe B, Allanore Y, Cantagrel A et al (2005) Tolerance and short term efficacy of rituximab in 43 patients with systemic autoimmune diseases. Ann Rheum Dis 64:913-920

27. Seror R, Sordet C, Gottenberg JE, Guillevin L, Masson C, Sibilia $\mathrm{J}$ et al (2005) Tolerance and efficacy of rituximab and changes in serum B cell biomarkers in patients with systemic complications of primary Sjogren's syndrome. Arthritis Rheum 52:378S

28. Carnahan J, Wang P, Kendall R, Chen $\mathrm{C}, \mathrm{Hu} \mathrm{S}$, Boone $\mathrm{T}$ et al (2003) Epratuzumab, a humanized monoclonal antibody targeting CD22: characterization of in vitro properties. Clin Cancer Res 9:3982S-3990S

29. Steinfeld SD, Tant L, Burmeister GR, Teoh NKW, Wegener WA, Goldenberg DM, Pradier O (2006) Epratuzumab (humanized antiCD22 antibody) in primary Sjogren's syndrome: An open-label Phase I/II study. Arthritis Res Ther 8:R129

30. Pers JO, d'Arbonneau F, Devauchelle-Pensec V, Saraux A, Pennec YL, Youinou P (2005) Is periodontal disease mediated by salivary BAFF in Sjogren's syndrome? Arthritis Rheum 52:2411-2414

31. Baker KP, Edwards BM, Main SH, Choi GH, Wager RE, Halpern WG et al (2003) Generation and characterization of LymphoStat-B, a human monoclonal antibody that antagonizes the bioactivities of B lymphocyte stimulator. Arthritis Rheum 48:3253-3265

32. Ramanujam M, Davidson A (2004) The current status of targeting BAFF/BLyS for autoimmune diseases. Arthritis Res Ther 6:197202

33. Szodoray P, Jonsson R (2005) The BAFF/APRIL system in systemic autoimmune diseases with a special emphasis on Sjogren's syndrome. Scand J Immunol 62:421-428

34. Bowman SJ, Sutcliffe N, Price E, Isenberg D, Goldblatt F, Regan M, Mathew R, Mulherin D, Rigby S, Hamburger J (2005) Measuring systemic disease activity in primary Sjögren's syndrome. Arthritis Rheum 52:376S

35. Vitali C, Palombi G, Baldini C, Benucci M, Bombardieri S, Covelli M, Del Papa N, De Vita S, Epis O, Gerli R, Govoni M, Maddali Bongi S, Maglione W, Migliarese S, Montecucco C, Orefice M, Priori R, Valesini G (2006) Measurement of disease activity in Sjögren's syndrome (sjs) by means of a new scale developed by the analysis of a cohort of patients collected by the study group for sjs of the itialian society of rheumatology. Ann Rheum Dis 65:606 (suppl II) 